\title{
CONCEPTS
}

\section{Wilderness Search Strategy and Tactics}

Ken Phillips, BS; Maura J. Longden; Bil Vandergraff; William R. Smith, MD; David C. Weber, BS; Scott E. McIntosh, MD, MPH; Albert R. Wheeler III, MD

From the Search and Rescue National Park Service-Washington Office, Washington, DC (Mr Phillips); National Park Service Climbing and Search and Rescue Ranger (Ms Longden); Grand Canyon National Park Backcountry Ranger (Mr Vandergraff); St. John's Medical Center, Jackson, WY (Dr Smith); University of Utah, Salt Lake City, UT (Mr Weber); University of Utah, Salt Lake City, UT (Dr McIntosh); St. John's Medical Center, Jackson, WY (Dr Wheeler).

\begin{abstract}
Reports of overdue persons are common for search and rescue personnel. Search incidents for missing persons are conducted following established industry standard practices, which are continuously refined through experience and the analysis of previous search operations. Throughout this process, elements of uncertainty exist, and the knowledge and experience of the searchers and search managers may influence the outcome significantly. A sound knowledge of current search tactics will help search and rescue medical providers function more effectively during search operations. Initial actions during a search incident include 3 primary tasks that must be accomplished on any search: investigation, containment, and then hasty search efforts. Concurrent with these initial actions are the establishment of the search area and a formal US National Incident Management System incident command system. That is essential for an efficient operation and will lay the groundwork for expanding the operation past the initial operational period. The goal of applying these standard search management practices is to allow searchers to maximize their efforts, reduce some of the inherent uncertainty, and most importantly, place searchers in a position to detect the missing person.
\end{abstract}

Key words: search, rescue, land, strategy, tactics, wilderness

\section{Introduction}

In early October, Ryan Powell, an accomplished ultrarunner, fails to call home as planned after a daylong trail run in Yosemite National Park. Becoming anxious as nightfall sets in and with a storm developing over the Sierra Nevada, his wife Linda contacts the National Park Service. Yosemite Search and Rescue (YOSAR) initiates an organized search effort. (This search scenario at Yosemite National Park was constructed to provide a practical understanding of how search management practices are applied in the field. The case is entirely fictional and is used only to demonstrate search management practices.)

Reports of overdue persons are common for search and rescue (SAR) personnel. Eighty percent of all search subjects are male. Hikers and hunters combined represent the largest portion of search subjects $(39 \%) .^{1(p 16-29)}$ Between 2010 and 2012, the National Park Service

Disclaimer: The views expressed in this paper are those of the authors and do not necessarily reflect the views of the National Park Service.

Corresponding author: Albert R. Wheeler III, MD, St John's Medical Center, Emergency Medicine, PO Box 7890, Jackson, WY 83002 (e-mail: wheelerdoc@mac.com). managed an average of approximately 3000 search incidents annually. ${ }^{2}$ Search incidents for missing persons are conducted following established industry standard practices, which are continuously refined through experience and the analysis of previous search operations.

\section{Land Search Background}

According to author Dennis Kelly, "The theory of search was born with operations research in World War II. The theory was used by the Office of Naval Research to cope with the menace of Nazi submarines." ${ }^{33}$ Kelly compiled statistics regarding lost person behavior and published Mountain Search for the Lost Victim (1973), which was the first ground search management textbook. ${ }^{3}$

Current land search management training in the United States has a foundation with the Managing the Search Function Course, originally developed in 1972 by the National Park Service at the Albright Training Center, Grand Canyon National Park. ${ }^{4}$ Although advances in technology have greatly improved the efficiency of search operations, the methods taught in that original course are still the foundation for the land search management techniques used today. 
After a subject is reported missing, the initial actions taken during the first operational period of 8 to 12 hours will normally locate the subject, and the situation is resolved. A 10-year review of US National Park Service search incidents (2003-2012) found that 96\% of all search incidents were resolved in less than 1 day through initial actions. ${ }^{2}$ These initial actions include 3 primary tasks that must be accomplished on any search: investigation, containment, and hasty search efforts. Concurrent with these initial actions are the establishment of the search area and a formal US National Incident Management System (NIMS) incident command system (ICS). That is essential for an efficient operation and will lay the groundwork for expanding the operation past the initial operational period.

When the subject is not located during the first operational period, the search then expands into an extended search operation. These extended search operations may last for days to weeks, spanning several operational periods and requiring a more detailed and systematic use of search management techniques. This paper provides a summary of initial search management actions and discusses when and how to expand the operation during extended incidents.

\section{Investigation}

Yosemite Ranger Dave Hope, the initial incident commander (IC) for the search, interviews Linda Powell by phone. The IC obtains detailed information about the missing subject, who had planned to run the Lyell Canyon-Vogelsang-Rafferty Creek Loop, which is a 20mile $(32 \mathrm{~km})$ route encompassing the Tuolumne Pass area (elevation 10,000 feet [3048 m]) in the eastern portion of the park. Using a lost person questionnaire, the IC obtains detailed personal information about the subject, including physical description, outdoor experience, health concerns, personal equipment he was carrying, and his personality traits. The IC learns that the subject has not been on this route previously and developed his trip plan from information he read on a trail running blog. The IC also learns that the subject intended to leave his cell phone in his vehicle parked at the trailhead. With an early winter storm setting in, the $I C$ evaluates the urgency of the incident based on a search urgency rating chart. Several factors, including traveling solo, known hazardous terrain, and the hazardous weather that is changing from freezing rain to snow in the area, are all given a very high urgency rating. These are considered "red flags" in the evaluation process, indicating that searching for the subject is an urgent priority and that a wait-and-see approach is not appropriate. Initial investigation efforts locate the subject's vehicle at the trailhead parking lot, indicating he is most likely still in the area (Figure 1).

A structured command and control organization must be applied to the search incident. Early establishment of the NIMS ICS is important. The first responder to an emergency becomes the initial IC and begins the investigation. As the incident expands in complexity, the initial IC is commonly relieved by a more experienced person. Comprehensive investigative efforts are immediately initiated from the onset of the search and will continue throughout the incident. Background information should be collected about the search subject through sources such as interviews with family and friends, social media, financial transactions, cell phone records, criminal history check, Internet searches, and so forth. This information, which becomes the subject profile, helps determine the search location. The time spent performing these tasks can save hours of searching if the appropriate information is collected.

Three distinct terms are used in search management to describe useful points of reference that should be determined during the investigation: point last seen (PLS), last known point (LKP), and initial planning point (IPP). The initial step is typically determining the location of the PLS, established by an eyewitness, for example. Clues located through the course of the search provide additional updated information on the subject's direction of travel and areas traveled. Although the subject may not be physically observed, a verifiable clue, such as a signature in a summit register, provides a LKP. Additional information discovered during a search may alter the PLS or LKP. The IPP is a reference point that does not change during an operation. It may be established as either a PLS or a LKP depending on which is closest to the missing subject based on their travel history. Initial search planning efforts and travel distance calculations are all based on the IPP. Establishment of these geographic locations will help determine the initial search area.

\section{Containment}

The IC delegates the role of incident investigator to another ranger so that he can remain focused as the IC. He activates a callout for additional trained SAR personnel. With the investigation efforts ongoing, the IC's next concern is to contain the subject and prevent the search area from expanding. He assigns a containment team to establish a camp at the Lyell Canyon (John Muir Trail) and Rafferty Creek Trail junction at Tuolumne Meadows. The IC makes radio contact with 2 trail crew employees camped to the south at Merced Lake Ranger Station $(6$ miles [10 km] from Vogelsang High 


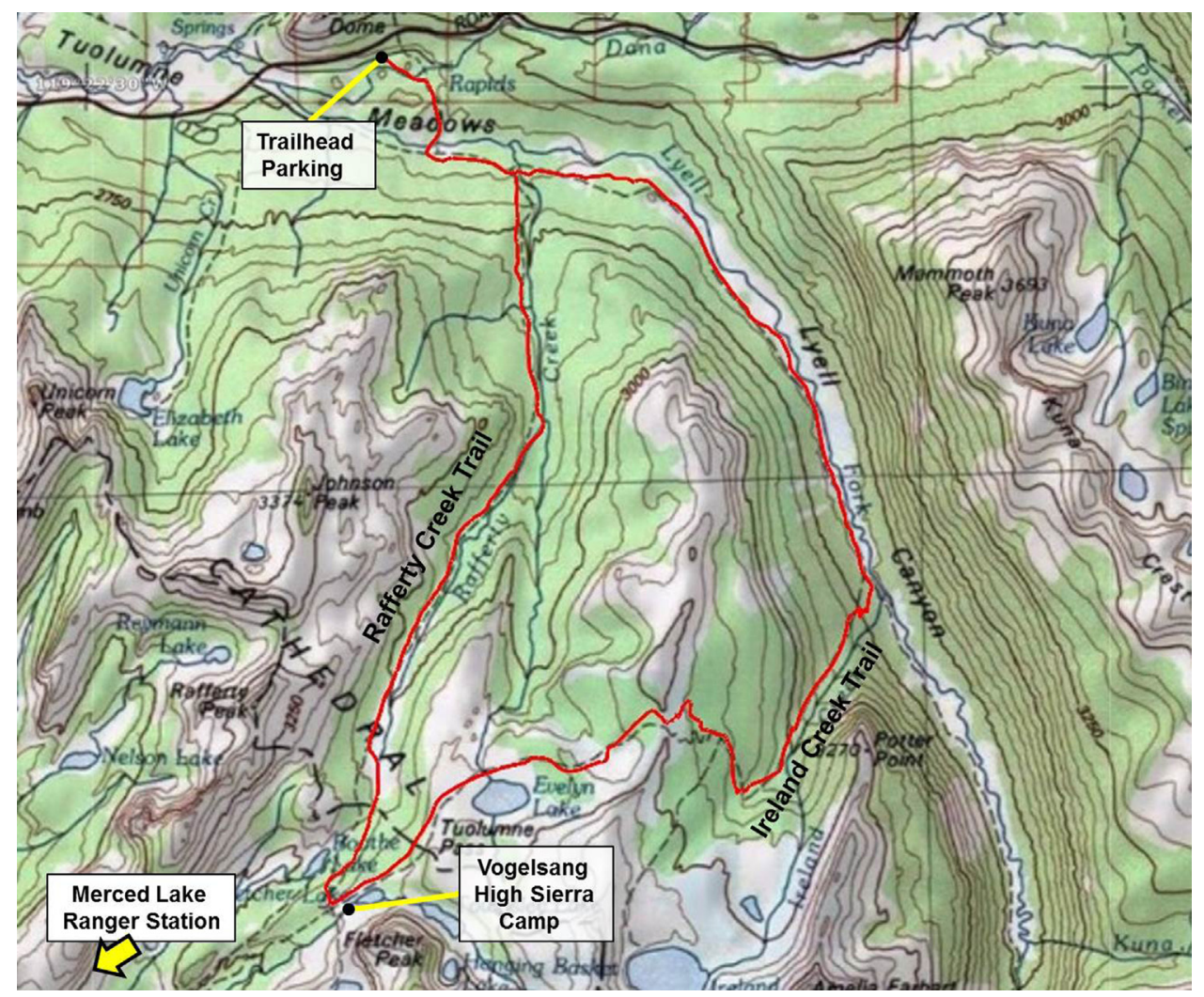

Figure 1. Lyell Canyon-Vogelsang Loop in Yosemite National Park. The route is a 20-mile (32 km) loop in the high country of Tuolumne Meadows that is extremely popular for multiple-day hikes.

Sierra Camp) and tasks them with establishing a trail block as an additional means of containment.

Containing the search subject early will prevent the search area from expanding exponentially. These efforts take into consideration many important factors such as past subject behavior, subject objectives, and other information obtained through the investigation. Containment teams stationed at strategic locations such as trailheads, roads, trail junctions, or lookout points serve to limit the subject's movement. Although these locations may actually be outside of the established search area, they typically lie along easily accessed areas and along natural borders adjacent to the search area.

Additional means of containment for a missing subject include the use of a lookout scanning from a promontory, roving patrols along a roadway, or track traps, which may be established in areas like a dry wash physically brushed smooth to highlight any subsequent foot travel later through the area. Investigation efforts also provide a means of "electronic containment" of a missing subject. Cell phone records may indicate whether a subject has left the search area or may assist in locating the subject. Financial records can also indicate whether a subject has used a credit or debit card outside the search area.

\section{Lost Person Behavior}

Predicting the actions or behaviors of a missing person is often the biggest mystery in a search. These behaviors have been categorized by activity and cognitive capabilities. The research into lost person behavior provides some useful planning data:

- Lost subjects will frequently follow travel aids, such as geographical paths of least resistance or trails. ${ }^{5(\mathrm{p} 137)}$

- One exception is very young children (1 to 3 years old), who have poor navigational skills and tend to wander aimlessly when lost. They seek natural shelters and because of their smaller size are harder to detect. They do not travel very far, and in $50 \%$ of cases in mountainous terrain, the children were found within 0.2 miles $(0.3 \mathrm{~km})$ of the IPP. ${ }^{1(\mathrm{p} 130)}$

- Somewhat older children (4 to 6 years old) have more developed navigational skills and are capable of traveling further. The children in $50 \%$ of these cases were found 0.5 miles $(0.8 \mathrm{~km})$ from the IPP. ${ }^{1(\mathrm{p} 135)}$

- Elderly subjects with severe dementia (including Alzheimer's) are much like very young children with 
respect to poor navigational skills. They tend to travel in the direction from which they departed until a physical barrier stops them. In the urban environment, $50 \%$ of all dementia subjects were found 0.7 miles $(1.1 \mathrm{~km})$ from the IPP. None of the dementia subjects called out for help to searchers, and $45 \%$ were found dead, ${ }^{5(\mathrm{p} 145)}$ which raises the urgency of implementing effective initial actions for subjects in this category.

- Hikers are very oriented to trails, and in $68 \%$ of cases become lost because of decision points, including trail junctions, or obscured trail conditions; $52 \%$ of hikers are found downhill from the IPP, which is the path of least resistance. However, a more recent phenomenon has been that hikers have moved uphill in an effort to obtain cell phone coverage. The median distance from the IPP in temperate mountainous terrain at which missing hikers are found is 1.9 miles $(3.1 \mathrm{~km}){ }^{1(\mathrm{p} 183-184)}$

It is helpful, at the onset of a search, to consider the answers to the following basic questions about subject behavior and to search accordingly: 1) is the subject mobile or immobile, and 2) is the subject responsive or unresponsive? As time elapses and intelligence or clues are obtained regarding the subject, these scenarios can become more specific regarding subject intentions, background, and the characteristics of the search area.

\section{Search}

The search commences with an initial action phase, which includes conducting hasty searches of the areas in which the subject is most likely to be found.

\section{HASTY SEARCH}

Two hasty search team teams were deployed that night in deteriorating weather to look for the subject. One team was sent up Rafferty Creek Trail toward Tuolumne Pass while the other searched up Lyell Canyon. The assignment called for both teams to rendezvous at the Vogelsang High Sierra Camp area (closed for the season) and bivouac for the night.

The objective of the hasty search is to locate the subject before significant time elapses (exponentially increasing the size of the search area). The hasty team can also intervene if the subject is in a hazardous situation. Although "hasty" suggests speed, the term refers to deployment of resources and not to the tactic of actual searching. "Slow is smooth, smooth is fast" is a commonly used mantra to help regulate the operational pace during this phase of a search. Because the vast majority of searches are resolved within the first 24 hours, a thorough hasty search must be performed to maintain these odds.

Hasty search teams should be familiar with the geographic area in question. They should possess the commensurate backcountry experience, carry the proper survival gear to be self-sufficient for an extended deployment (typically 24 to 36 hours), and understand the principles of search management. Composing hasty teams of 3 or more members allows them to be selfsufficient in case of injury or illness of a hasty team member. Hasty teams should also have diversified skills, possibly including a medical provider, search dog and handler, and a team leader with knowledge of the area.

Deploying hasty teams from both the LKP and containment locations allows teams to work toward each other. This tactic cuts the workload significantly and provides a different visual perspective if the teams continue toward the starting point of the respective team. In some areas, hasty teams can conduct sound sweeps using whistles. This is an effective attraction tactic often used during the night or in timbered areas. However, it requires coordination, organization, and practice to be effective and to not confuse search teams in adjacent areas.

With the hasty teams properly briefed and deployed on their assignments, the IC orders additional personnel and activates a plans section to support this search incident as it quickly escalates in complexity (Figure 2). This escalation of efforts through concurrent actions will allow for an efficient increase in search efforts during the next operational period.

While initial actions are taking place, concurrent actions such as establishment of the search area and planning for the next operational period are begun by the command staff. That involves a dramatic escalation of incident planning activities being initiated. A more systematic deployment of resources is necessary to make certain there are no gaps in search area coverage. The ICS should be well established at this point and can now be expanded to maintain adequate command and control.

The classic type of an organized search that could be implemented as the search operation expands is known as a grid search. That means working slowly through the entire area, perhaps from one side to the other or from the center spiraling outward. In a large wilderness search area, it is often impractical to employ grid search techniques, owing to the amount of time and personnel required. That is when search theory and tactics become important.

\section{ESTABLISHING THE SEARCH AREA}

During the hasty search efforts, the search team in Lyell Canyon contacts 2 hikers who had spoken with the 


\section{Powell Search \\ Yosemite $\begin{aligned} & \begin{array}{l}\text { National Park } \\ \text { California }\end{array} \\ & \text { Yos }\end{aligned}$}

INCIDENT COMMANDER

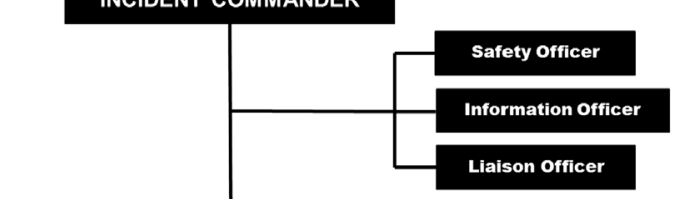

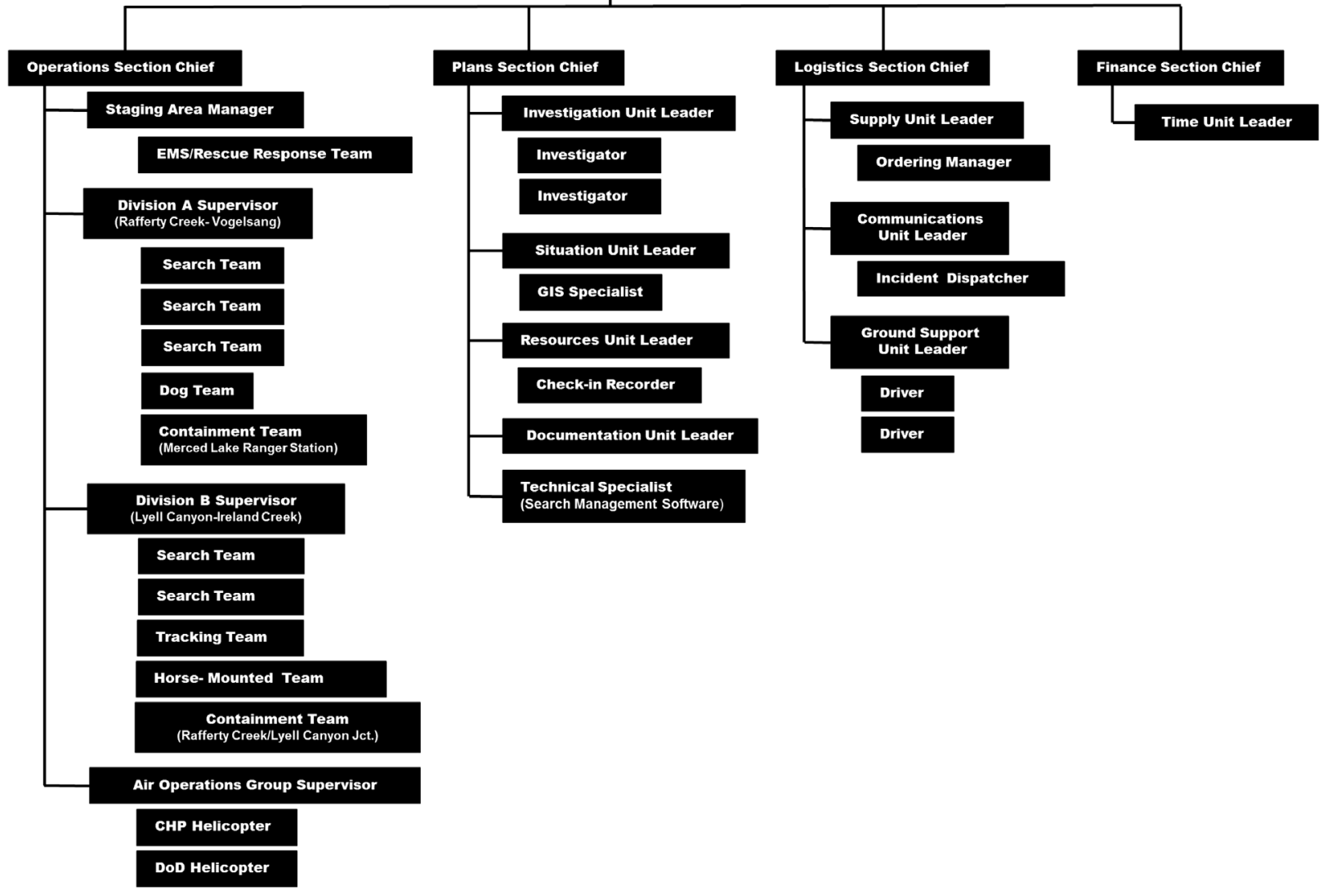

Figure 2. The incident command system (ICS) chart reflects the positions activated to support this search incident as it escalates in complexity. EMS, emergency medical services; CHP, California Highway Patrol; DoD, Department of Defense; GIS, geographic information system.

subject that same day at around 1:00 p.m. on the Ireland Creek Trail. At that time, the subject was running comfortably up the trail on the established route. They further stated that weather was deteriorating and the cloud ceiling was approaching 10,000 feet $(3048 \mathrm{~m})$. This eyewitness sighting, which is the PLS, is more recent than the LKP of the vehicle and will be delineated as the IPP as incident planning efforts are initiated (Figure 3).

The following 4 methods may be used to establish the search area, and they are typically applied in the order presented: theoretical search area, statistical search area, subjective factors, and deductive reasoning.

A theoretical search area is the possible distance that a subject could have traveled from the IPP if the subject was able to travel in any direction unhindered by terrain. It is determined by an estimated rate of travel multiplied by the amount of time that the subject has had to travel. When plotted on a search area map, a theoretical search area is illustrated as a circle with the IPP at its center.

The plans section calculates a theoretical search area (Figure 4) based on the subject being missing for 10 hours and the conservative estimate that hikers travel 2 miles per hour, which creates a theoretical search area with a radius of 20 miles $(32 \mathrm{~km})$. This conservative approach will increase the chances of capturing the subject within the search area. This theoretical search area is 1256 square miles $\left(3253 \mathrm{~km}^{2}\right)$. For comparison, Yosemite National Park is 1190 square miles (3082 $\mathrm{km}^{2}$ ). That creates a useful planning tool to indicate how far from the IPP additional containment efforts may be needed. In this case, posting flyers and checking all lodging in Yosemite Valley (western perimeter of theoretical area) would be useful to help locate the 


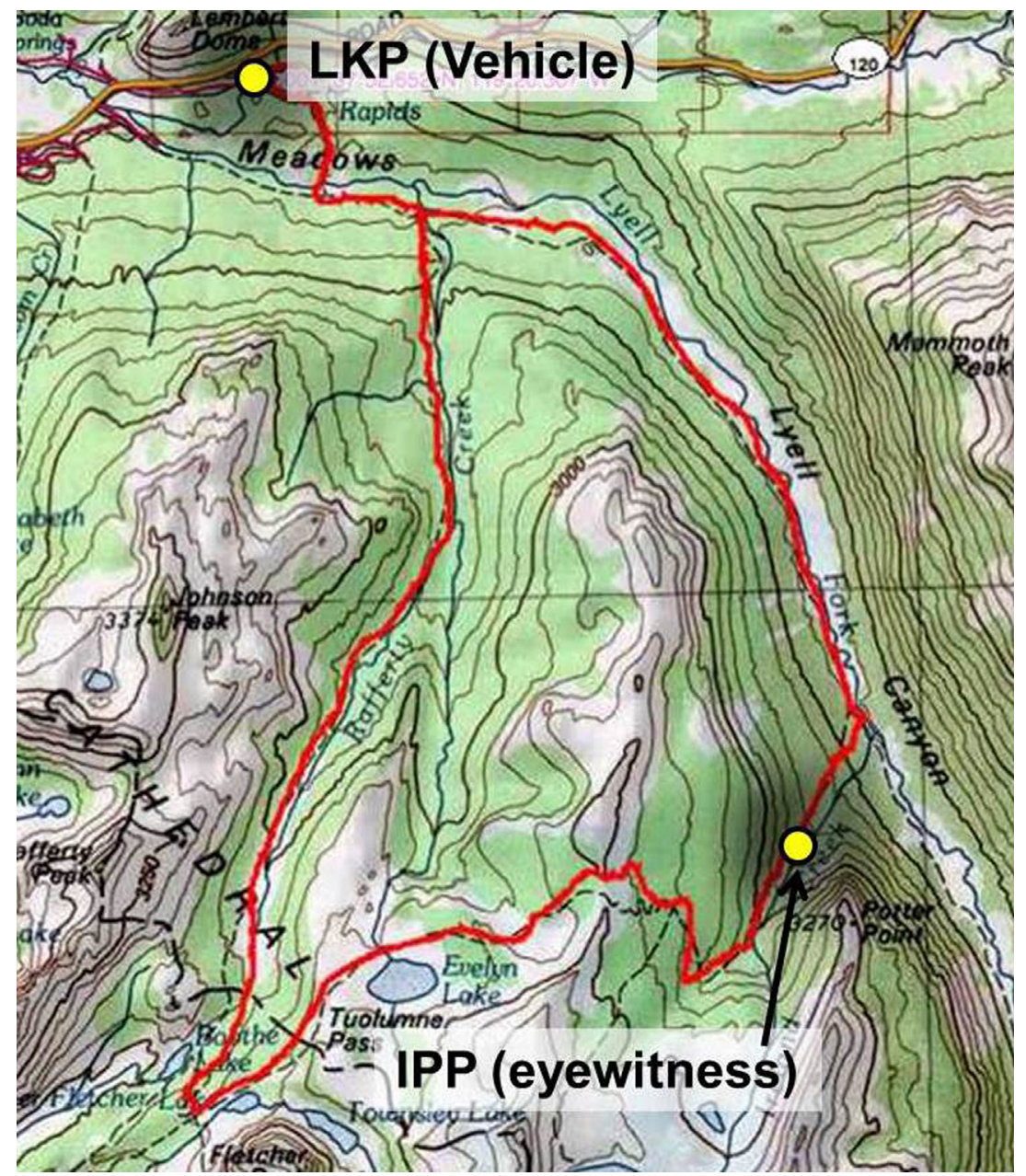

Figure 3. Last known point (LKP) and initial planning point (IPP) are identified.

subject or perhaps a witness who encountered him on the trail. However, a search of this entire area would be impractical.

A statistical search area is based on data derived from previous incidents that reflects the distance other subjects have traveled from the IPP, given similar conditions. Lost Person Behavior by Robert J. Koester ${ }^{1}$ is a valuable reference that provides statistics based on the data analysis of $>50,000$ lost person cases. Statistics regarding lost person behavior are commonly used in establishing a search area and in determining high probability locations to be searched.

Experience with lost runners reveals that they are found within 1 mile $(1.4 \mathrm{~km})$ of the IPP in $25 \%$ of cases and 2.1 miles $(3.4 \mathrm{~km})$ in $75 \%$ of cases. ${ }^{1\left(\mathrm{p}^{227)}\right.}$ Applying this information indicates that a search area with a significant chance of including the subject would involve establishing a search area 2 miles from the IPP. Occasionally, a runner will travel more than 2 miles in linear distance from the IPP; however, the search area can be expanded later if initial search efforts provide negative results. It is critical, though, to start the search in the highest likelihood areas, and applying lost person behavior principles provides this initial guidance.

The planning section chief utilizes a statistical search area that represents $75 \%$ of all lost runners, ${ }^{11(p 227)}$ generating an area with a radius of 2.1 miles $(3.4 \mathrm{~km})$ from the IPP (Figure 5).

A subjective search area considers factors that exist for a specific incident and location. Factors may include terrain and environmental conditions, history from previous searches, "gut feelings," and physical or mental limitations of the subject.

A retrospective review of search incidents in the Lyell Canyon-Vogelsang Loop is conducted by the plans section to include appropriate areas within the search area. Where have other hikers going up the Ireland Creek Trail become disoriented, and what did they do? Have other hikers 


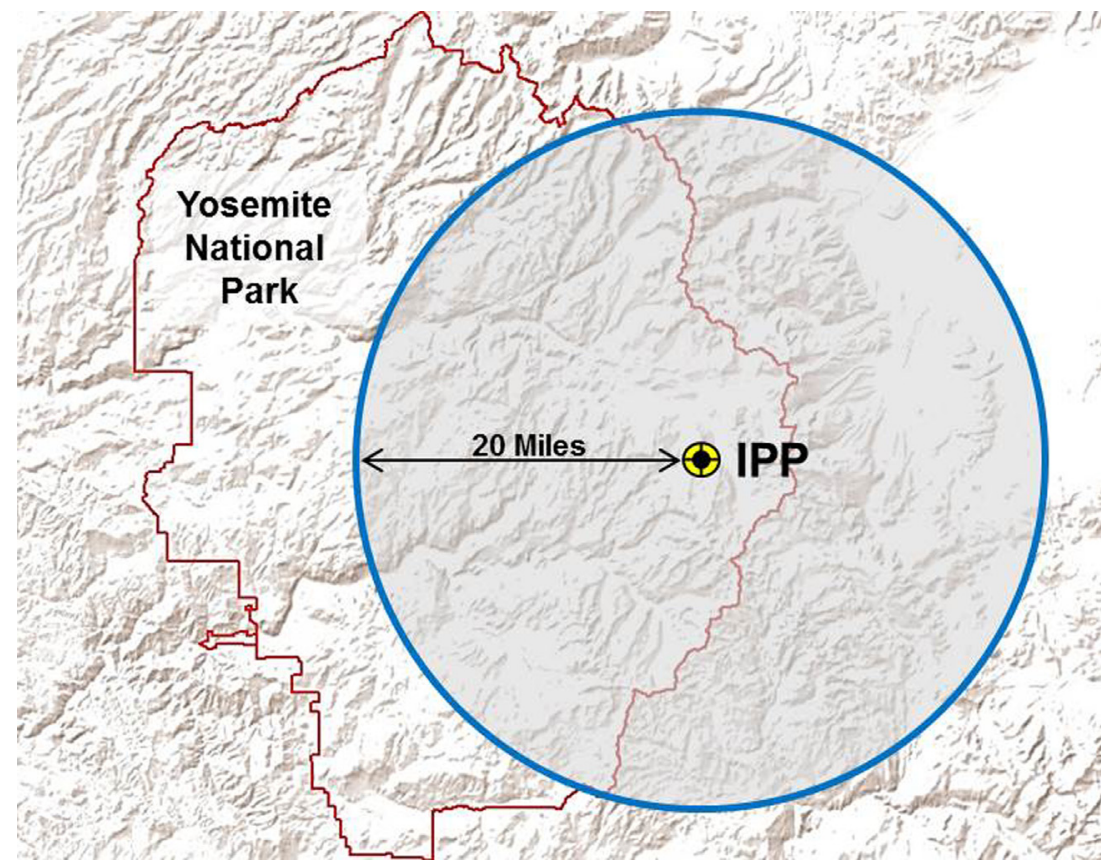

Figure 4. The theoretical search area is established with a radius of 20 miles $(32 \mathrm{~km})$, which creates an area of 1256 square miles $\left(3253 \mathrm{~km}^{2}\right)$. IPP, initial planning point.

become disoriented at the Vogelsang Trail Junction, and what direction did they go? The experience of Yosemite SAR personnel reveals the following: footing on trails and exposed rock surfaces becomes treacherous in hazardous weather; visual navigation is impaired by a low cloud ceiling associated with a storm, and trail runners carry little, if any, survival gear, forcing them to seek natural shelter.

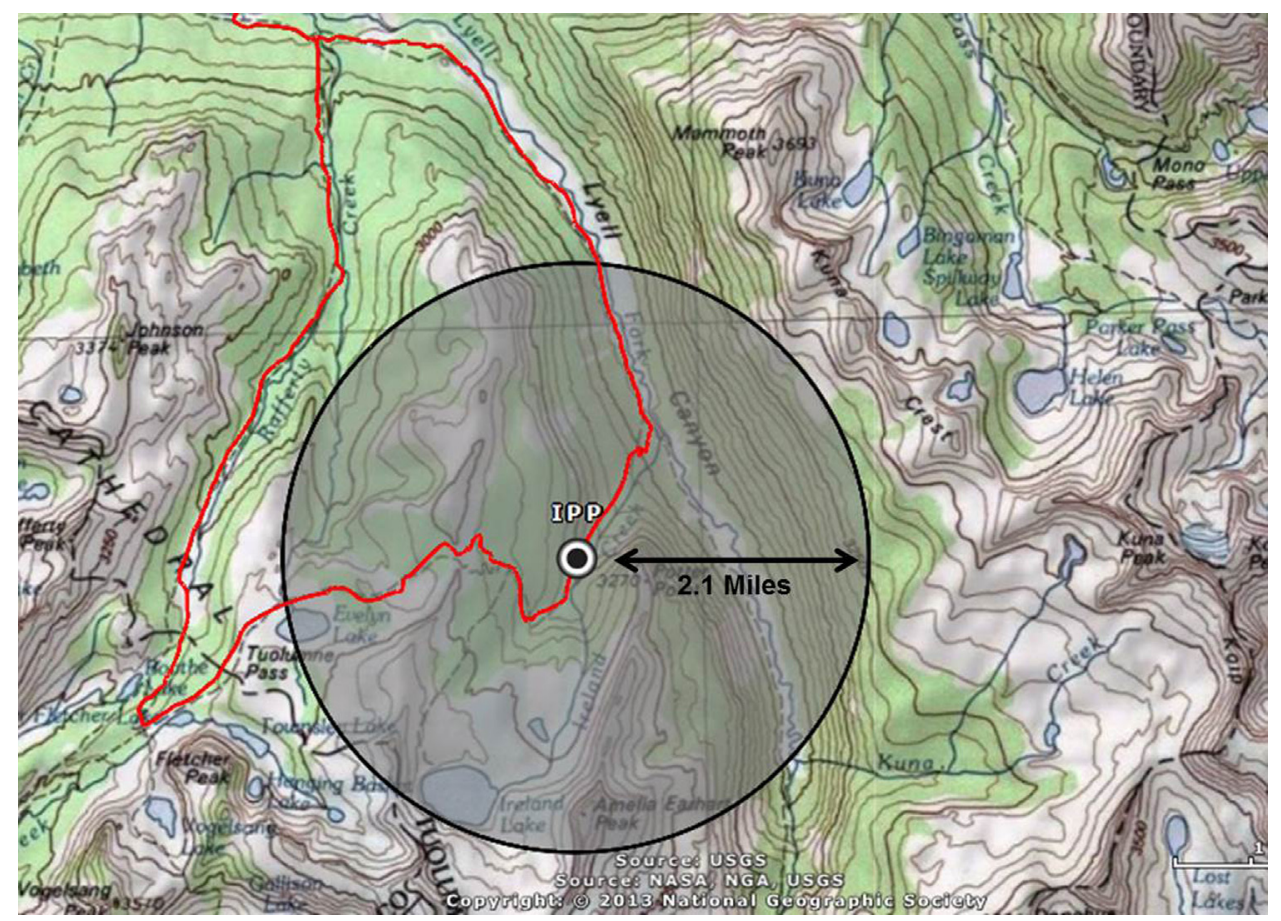

Figure 5. Statistical search area. Lost person behavior statistics reflect that $75 \%$ of missing runners are located within $2.1 \mathrm{miles}(3.4 \mathrm{~km})$ of the initial planning point (IPP). 
A deductive reasoning approach is a method of systematically analyzing the circumstances surrounding the subject who is lost or missing. The outcome of the analysis is then applied to the establishment of the search area. For example, realizing that a hiker is known to travel off trails will result in expanding the search area to include these areas. Knowing that a photographer had a specific destination for that day will help establish the search area in that general direction.

In the deteriorating weather conditions, the subject may have become disorientated while ascending the Ireland Creek Trail or before traveling on the Rafferty Creek Trail. In such a situation, the subject may have followed a geographical travel aid downhill, such as a drainage, away from the Ireland Creek Trail, believing he is on the Rafferty Creek Trail. A lack of overnight equipment or additional clothing may increase the likelihood that the subject is suffering from fatigue or hypothermia and will be unresponsive to search personnel.

Using the information from these 4 methods permits planners to construct a detailed search area. The perimeter of this search area is then delineated on a map, before any segmentation within its boundaries.

\section{SEARCH AREA SEGMENTATION}

Once the initial hasty search has been completed and an updated area has been established, the search area is subdivided into manageable units for searchers.
Segmentation is based on an analysis of the terrain and consideration of lost person activity and predicted behavior. Segmentation enables search managers to prioritize the search efforts, assign and track search resources in the field, and identify search coverage and effectiveness. Segments are based on topography and vegetation, and the boundaries between segments should be recognizable by searchers in the field. A common tendency is to create segments that are too large without full consideration given to the terrain, density of vegetation, weather conditions, or type of resources assigned to search the area. A segment should be sized so that the assigned resources are able to search it completely within an operational period. As a general rule, ground searchers may be assigned an area of 0.25 square miles $\left(0.65 \mathrm{~km}^{2}\right)$ or 160 to 200 acres in an operational period. ${ }^{5(\mathrm{p} 176)}$

Terrain in which the subject could not have traveled, or where it is impractical to search, may be initially excised from the search area. Travel aids that may provide easier or inviting routes for travel (such as trails, ridge tops, and drainages) should be labeled as separate segments (Figure 6).

After the segmentation of the search area, each segment is assigned a value representing the "probability of area" (POA), or the chance (percent) that the subject is in a given segment (Figure 7). These values are derived by a group of persons familiar with the particular search incident who participate in a subjective evaluation of the missing subject location. Each member of the initial

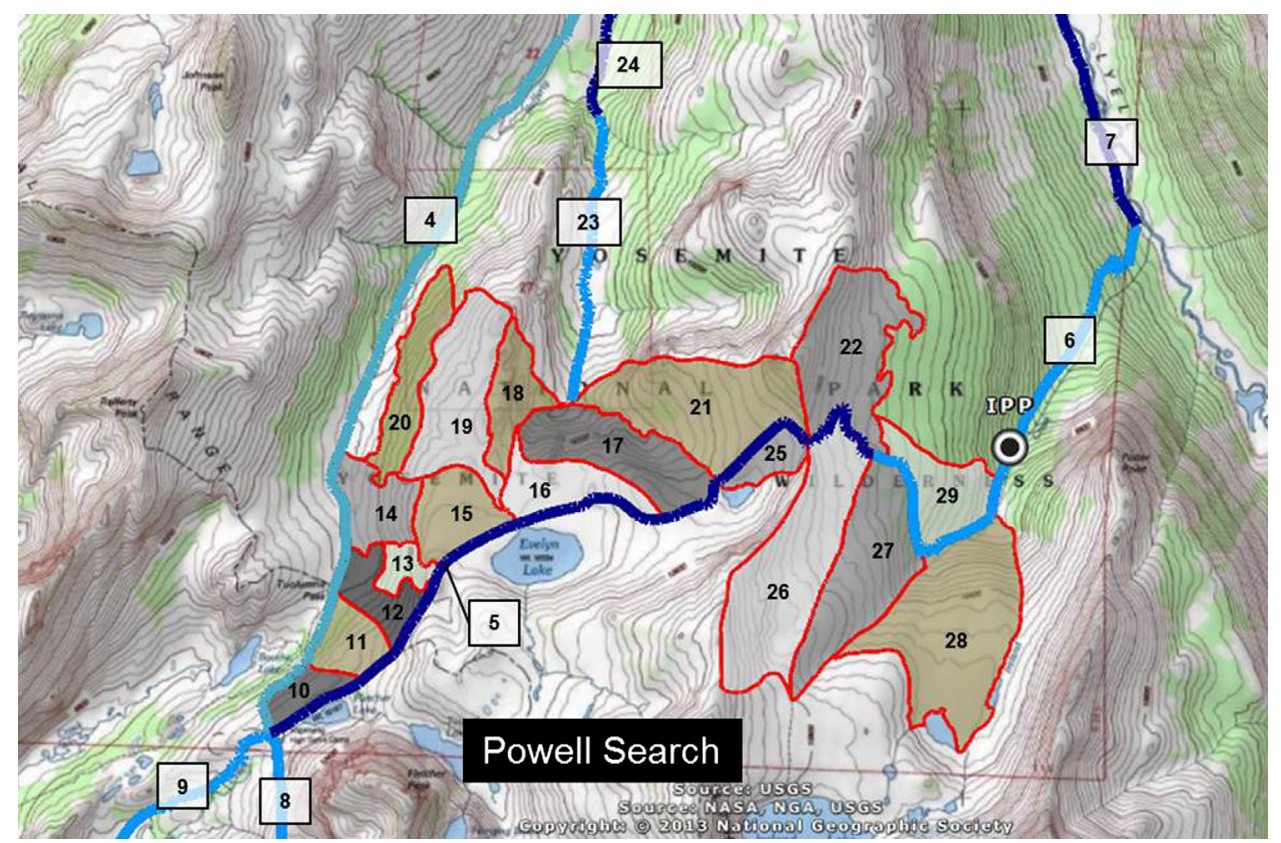

Figure 6. Search area segmentation. Search segments include linear travel aids (eg, trails, ridges, drainages), as well as open areas surrounded by discernible boundaries. IPP, initial planning point. 


\section{Ranked By POA}

\begin{tabular}{|c|c|c|c|}
\hline Segment & POA & $\mathbf{1 2}$ & $3.03 \%$ \\
\hline $\mathbf{3 0}$ (ROW) & $7 \%$ & $\mathbf{2 5}$ & $3.01 \%$ \\
\hline $\mathbf{2 0}$ & $5.88 \%$ & $\mathbf{1 6}$ & $2.69 \%$ \\
\hline $\mathbf{1 9}$ & $5.88 \%$ & $\mathbf{2 6}$ & $2.36 \%$ \\
\hline $\mathbf{2 4}$ & $5.38 \%$ & $\mathbf{2 7}$ & $2.36 \%$ \\
\hline $\mathbf{2 3}$ & $4.58 \%$ & $\mathbf{2}$ & $2.36 \%$ \\
\hline $\mathbf{1 8}$ & $4.53 \%$ & $\mathbf{5}$ & $2.34 \%$ \\
\hline $\mathbf{1 7}$ & $4.2 \%$ & $\mathbf{6}$ & $2.34 \%$ \\
\hline $\mathbf{1 3}$ & $4.2 \%$ & $\mathbf{9}$ & $2.32 \%$ \\
\hline $\mathbf{2 1}$ & $4.19 \%$ & $\mathbf{2 8}$ & $2.03 \%$ \\
\hline $\mathbf{1 4}$ & $4.19 \%$ & $\mathbf{2 9}$ & $2.03 \%$ \\
\hline $\mathbf{4}$ & $3.69 \%$ & $\mathbf{3}$ & $2.02 \%$ \\
\hline $\mathbf{1 1}$ & $3.36 \%$ & $\mathbf{7}$ & $2 \%$ \\
\hline $\mathbf{2 2}$ & $3.34 \%$ & $\mathbf{8}$ & $1.67 \%$ \\
\hline $\mathbf{1 5}$ & $3.03 \%$ & $\mathbf{1}$ & $0.67 \%$ \\
\hline 10 & $3.03 \%$ & TOTAL & $\mathbf{1 0 0} \%$ \\
\hline
\end{tabular}

Figure 7. Initial probability of area (POA) values from a Mattson consensus conducted for this search. ROW, rest of world.

consensus team assigns a number, and then an average value for each segment is obtained. The segments with the higher POA values then receive higher search priority. ${ }^{1(\mathrm{p} 316)}$ This process, conducted only once, is known as a Mattson consensus or O'Connor consensus. The probability that the subject is not in the search area, such as having returned home or being at a local hotel, should always be considered, and is known as the "rest of the world" (ROW); it is also assigned a POA value (Figure 7).

\section{COVERING THE SEARCH AREA}

Once the process outlined above identifies the search area segments and POAs for a missing subject, searchers are sent into the field to search for the subject based on this information. Upon their return, assuming the subject is not located, the searchers are subjectively polled to determine how well an area has been covered or searched. This process can be very imprecise, however. The concept of coverage attempts to solve these problems. The reality, however, is that no area can be covered or searched with $100 \%$ assurance of locating the search subject.

Locating a search subject is contingent on the searcher's ability to detect the lost subject in a given environment. Numerous variables (competence, speed, spacing, vegetation, topography, lighting, and so forth) affect the searcher's ability. With these variables in mind, a value representing the searchers' confidence in their search area coverage is subjectively determined. This is known as "probability of detection" (POD), or the chance of locating the subject in a given area during a given search effort (eg, "I had a 10\% chance of finding the subject").

To address the inherent subjectivity in this process, search professionals have researched techniques that will derive more accurate and objective values representing coverage. In land searches, determining POD from coverage depends on the variables addressed above. A basic and simple technique to determine coverage, called a critical separation exercise, is conducted in an area before searching. An object is placed on the ground and searchers move away from it until they reach the last point at which it is detectable. The average distance of searchers from the object is the maximum distance they should be apart while searching. Subjectivity is still present when extrapolating POD from this exercise as searchers are asked at the completion of their assignment, if 10 of these objects were in the search area, how many would you have found? Their guesses, represented by a percentage, would be the POD.

Global positioning system (GPS) tracking can be a valuable asset for graphically displaying coverage. However, GPS tracking results in a one-dimensional line on a map that graphically shows where a searcher went but 


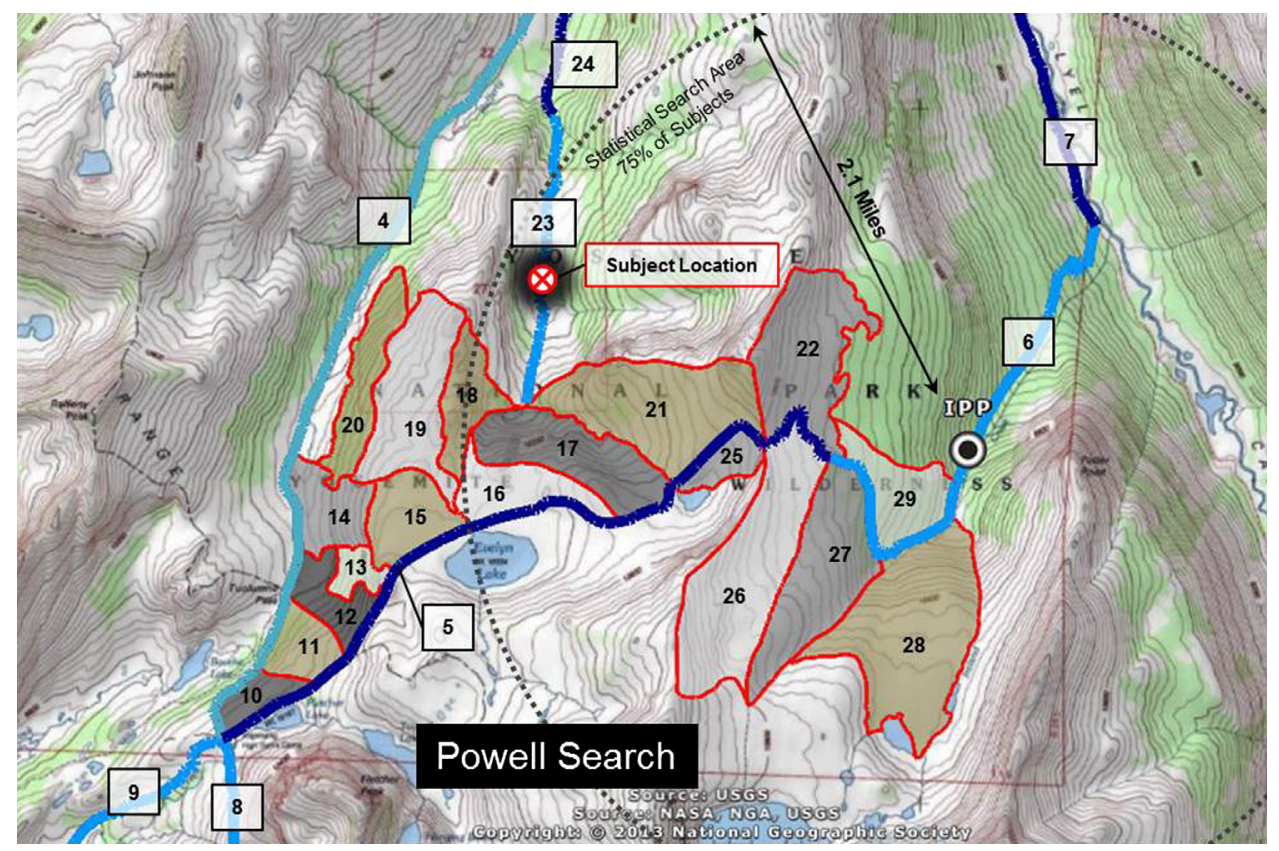

Figure 8. Location of the subject in segment 23, within the statistical search area. IPP, initial planning point.

does not reflect the conditions or environment, nor does it provide a POD value for the searcher doing the tracking.

After a segment is searched and a POD value is assigned, an updated POA value is computed, often using computer modeling. The POA value of a searched segment will decrease, while other segments not searched will have a POA increase. After several operational periods and numerous deployments of searchers into segments, a trend will emerge that may shift the POA from one segment to another. When displayed in a table, these figures become useful in allocating resources for the next operational period.

\section{Conclusion}

The next morning, search efforts are escalated, with a break in the weather permitting the use of aircraft. Aerial searching is initiated, and several teams are inserted directly into the search area by helicopter. One team is assigned to search any likely paths of travel north of the Ireland Creek Trail in segment 17. Upon reaching the junction with segment 23 , they observe some recent tracks that are protected from the weather by small trees. This clue provides a direction of travel heading north into the east fork of Rafferty Creek (segments 23 and 24). A short time later Ryan Powell is located along the east fork of Rafferty Creek in segment 24 (Figure 8). After becoming disoriented in the low visibility of the storm, Ryan got off the Ireland Creek Trail and began following the east fork drainage, believing he was in the west fork. After being unable to locate the trail and with the weather worsening, he fortunately located a rock overhang and used an emergency blanket combined with a plastic trash bag to bivouac overnight.

Searching for a missing subject involves a systematic process of investigation, planning, and management of the search. Throughout this process, elements of uncertainty exist, and the knowledge and experience of the searchers and search managers can influence the outcome significantly. Ultimately, the goal of applying standard search management practices is to allow searchers to maximize their efforts, reduce some of the inherent uncertainty, and most importantly, place searchers in a position to find the missing subject.

\section{Acknowledgments}

Special thanks to John Dill, NPS Yosemite Search and Rescue, for his help with the technical information used in the search scenario. The map illustrations, as noted, were generated in ArcGIS Explorer software by Esri, Redlands, California.

\section{References}

1. Koester RJ. Lost Person Behavior. A Search and Rescue Guide on Where to Look-for Land, Air, and Water. Charlottesville, VA: dbS Productions; 2008. 
2. US National Park Service data: annual search and rescue reports. Data from 2003-2012. Available at: http://www. nps.gov/foia.htm. Accessed January 29, 2014.

3. Kelly D. Mountain Search for the Lost Victim. Montrose, CA: Dennis E. Kelly; 1973.
4. Setnicka T. Wilderness Search and Rescue: A Complete Handbook. Boston, MA: Appalachian Mountain Club; 1981.

5. Hill KA, ed. Managing the Lost Person Incident. 2nd ed. Centreville, VA: National Association of Search and Rescue; 2007. 